\title{
Prevalence of parasitic contamination of raw vegetables in Nakhon Si Thammarat province, southern Thailand
}

\author{
Chuchard Punsawad ${ }^{1,3^{*}}$ D, Nonthapan Phasuk ${ }^{1,3}$, Kanjana Thongtup ${ }^{1}$, Surasak Nagavirochana ${ }^{1}$ and \\ Parnpen Viriyavejakul ${ }^{2}$
}

\begin{abstract}
Background: Soil-transmitted helminth (STH) infections are major public health problems in poor and developing countries that require fecal contamination of the environment for transmission. The consumption of raw vegetables without proper washing is one of the main routes of intestinal parasite acquisition. Therefore, this study was designed to detect the prevalence of intestinal parasitic contamination in commonly consumed raw vegetables sold in three central open-air markets in Nakhon Si Thammarat province, southern Thailand.

Methods: A total of 265 fresh vegetable samples consisting of peppermint, lettuce, coriander, leek, gotu kola, celery, Chinese cabbage, culantro, Thai basil, and Chinese morning glory were purchased from three central open-air markets in the Mueang, Thasala and Sichon districts from December 2016 to March 2017. Each sample was washed with physiological saline, shaken for $15 \mathrm{~min}$, and then allowed to sediment. Finally, sedimentation was performed via the sedimentation concentration technique and examined using light microscopy for the detection of pathogenic parasites.

Results: The overall prevalence of parasitic contamination was 35.1\% (93/265). The most predominant parasite was hookworms (42.9\%), followed by Strongyloides stercoralis (10.6\%), Trichuris trichiura (2.6\%), Ascaris lumbricoides (2.6\%), and Toxocara spp. (2.6\%). The highest level of contamination was found in celery, with a prevalence rate of 63.3\% (19/30), while the lowest contamination level was found in Chinese morning glory, with a prevalence rate of $2.0 \%(2 / 30)$. The prevalence of intestinal parasite contamination in Mueang district (51.5\%) was significantly higher than that in Thasala district (17.9\%) and Sichon district (30.6\%) $(P<0.001)$.

Conclusion: The results of the present study demonstrate that consumption of vegetables with parasite contamination in this area represents a potential route for the transmission of parasitic infection, particularly hookworm infection. Therefore, it is necessary for health authorities to educate consumers about the proper washing of vegetables prior to consumption. Preventive methods such as wearing gloves and washing hands after handling vegetables should also be advocated to sellers who are at risk of acquiring STH infections via skin penetration.
\end{abstract}

Keywords: Parasitic contamination, Raw vegetables, Intestinal parasites, Thailand

\footnotetext{
* Correspondence: chuchard.pu@wu.ac.th

'School of Medicine, Walailak University, 222 Thasala district, Nakhon Si

Thammarat 80161, Thailand

${ }^{3}$ Tropical Medicine Research Unit, Research Institute for Health Sciences,

Walailak University, 222 Thasala district, Nakhon Si Thammarat 80161,

Thailand

Full list of author information is available at the end of the article
}

(c) The Author(s). 2019 Open Access This article is distributed under the terms of the Creative Commons Attribution 4.0 International License (http://creativecommons.org/licenses/by/4.0/), which permits unrestricted use, distribution, and reproduction in any medium, provided you give appropriate credit to the original author(s) and the source, provide a link to the Creative Commons license, and indicate if changes were made. The Creative Commons Public Domain Dedication waiver (http://creativecommons.org/publicdomain/zero/1.0/) applies to the data made available in this article, unless otherwise stated. 


\section{Background}

Parasitic infections represent a major global public health problem. The burden of parasitic infections often affects developing countries, which frequently lack good sanitization and personal hygiene practices. Moreover, environmental factors such as climate, geography, temperature, soil type, and rainfall also play important roles that contribute to the prevalence of parasitic infections.

In southern Thailand, the most prevalent parasitic infection among all age groups has been soil-transmitted helminth (STH) infections, especially hookworm infection [1-4], which may transmit to humans through either skin penetration or the ingestion of its larvae [5].

The consumption of fresh vegetables is a common eating habit among people in southern Thailand. Further, healthy food trends in Thailand are now focused on sufficient daily vegetable consumption, as this could help prevent major diseases, such as cardiovascular disease and certain cancers. The $\mathrm{WHO}$ also recommended the intake of a minimum of $400 \mathrm{~g}$ of fruit and vegetables per day for micronutrient supplementation as well as the prevention of the aforementioned chronic diseases [6]. However, eating raw vegetables may also lead to the transmission of certain human pathogens (fresh fruits and vegetables are vectors for the transmission of human pathogens) [7]. Several studies have reported the parasitic contamination of fresh vegetables in many countries around the world, for example, Arba Minch town, southern Ethiopia [8], Khartoum state, Sudan [9], Benha, Egypt [10], Accra, Ghana [4], Mazandaran province, northern Iran [11], Poland [12], and Metro Manila, Philippines [13]. Parasites and protozoa that were common contaminants included Ascaris lumbricoides, Cryptosporidium spp., Entamoeba histolytica/dispar, Enterobius vermicularis, Giardia intestinalis, hookworm, Hymenolepis spp., and Trichuris trichiura [4, 8-12, 14]. These contaminants could result from water used to moisten vegetables and postharvesting handling methods $[8,9,15]$.

Nakhon Si Thammarat province is an endemic area for STH infection [3]. To date, there have been no reports on parasitic vegetable contamination in this area. Therefore, the main aim of this study was to determine the prevalence of parasitic contamination in commonly consumed vegetables in Nakhon Si Thammarat province, southern Thailand.

\section{Methods}

\section{Study area}

A cross-sectional study was conducted from December 2016 to March 2017 in Nakhon Si Thammarat province, which is located in southern Thailand approximately $800 \mathrm{~km}$ from Bangkok, the capital of Thailand. This area has a tropical rainforest climate and is located at the geographical coordinates of $8^{\circ} 43^{\prime} 10^{\prime \prime} \mathrm{N}$ latitude and $99^{\circ}$ $45^{\prime} 6$ " $\mathrm{E}$ longitude. The average annual temperature is $28.2^{\circ} \mathrm{C}$, and approximately $1702.6 \mathrm{~mm}$ of precipitation falls annually (Climatological Center, Thai Meteorological Department, Annual report 2015). According to official statistic registration systems, the total population in this area is approximately $1,557,482$. Fresh vegetable samples were purchased from three central open-air markets located in Mueang (the capital district of Nakhon Si Thammarat province), Thasala (approximately $30 \mathrm{~km}$ away from the capital district) and Sichon districts (approximately $70 \mathrm{~km}$ away from the capital district) (Fig. 1). The fresh vegetables sold in these markets were brought from different farms and agricultural areas in different parts of Nakhon Si Thammarat province.

\section{Sample collection}

A total of 265 fresh vegetable samples including 10 different types that are frequently consumed without cooking were randomly purchased from sellers in three central open-air markets. The fresh raw vegetable samples used in this study included peppermint (Mentha $x$ piperita), lettuce (Lactuca sativa), coriander (Coriandrum sativum), leek (Allium porrum), gotu kola (Centella asiatica), celery (Apium graveolens), Chinese cabbage (Brassica rapa

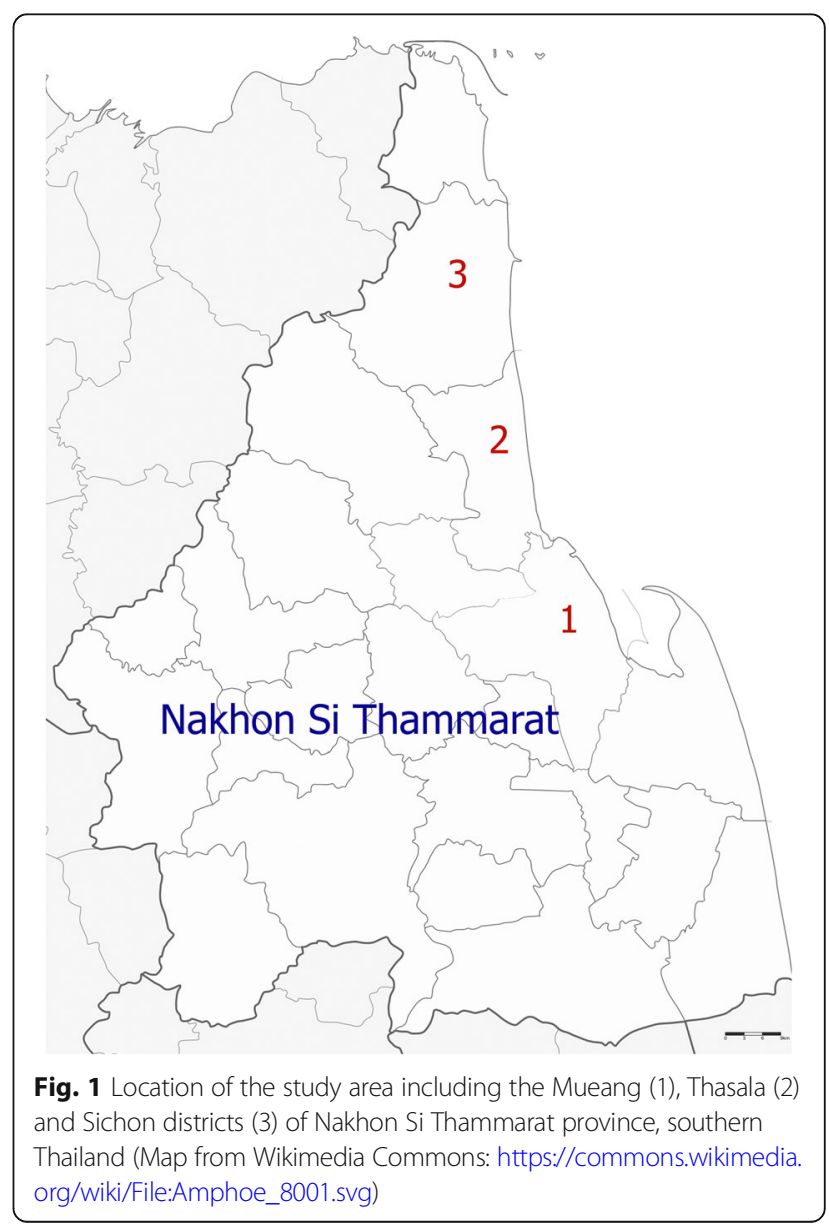


subsp. pekinensis), culantro (Eryngium foetidum), Thai basil (Ocimum basilicum), and Chinese morning glory (Ipomoea aquatica). The pictures of vegetable samples were demonstrated in Fig. 2. The fresh vegetable samples were collected in clean, labeled plastic bags and transported immediately to the parasitology laboratory at the School of Medicine, Walailak University for parasitic examination.

\section{Detection of intestinal parasites}

Fresh vegetable samples weighing $200 \mathrm{~g}$ were washed with $1000 \mathrm{~mL}$ of physiological saline solution $(0.9 \%$ sodium chloride) and shaken for $15 \mathrm{~min}$ in order to separate the parasites from vegetables. Then, the washing water was collected and left overnight to allow sedimentation. Afterward, the supernatant was decanted, and the remaining washing water was transferred to $12 \mathrm{~mL}$ conical tubes. To concentrate the parasitic stages, the sediment was centrifuged at $2000 \times \mathrm{g}$ for $15 \mathrm{~min}$. After centrifugation, the supernatant was carefully removed without shaking. Then, the sediment was agitated gently and examined under a light microscope using $10 \times$ and $40 \times$ objectives. To increase the chance of parasite detection, three slides were prepared from each sample by two independent investigators.

\section{Statistical analysis}

Data analysis was performed with IBM SPSS Statistics for Windows, Version 23.0. Armonk, NY: IBM Corp. Qualitative variables were described by frequency (percentage). A chi-squared test was used to compare the rate of parasitic contamination among different types of vegetable and among different markets. A $p$-value less than 0.05 was considered statistically significant.

\section{Results}

A total of 265 fresh vegetable samples were examined for the presence of parasite contamination. The results of parasitic contamination in vegetable samples are shown in Table 1. The parasites detected in vegetable samples were hookworm, Strongyloides stercoralis, Trichuris trichiura, Ascaris lumbricoides, and Blastocystis spp. Pictures of some of the parasites found in this survey were demonstrated in Fig. 3. The overall rate of intestinal parasite detection was $35.1 \%(93 / 265)$ in all vegetable samples. The highest rate of contamination was found in celery [63.3\% (19/30)] while the lowest was found in Chinese morning glory [6.8\% (2/30)] (Table 1). The highest rate of hookworm contamination was found in celery, but not Thai basil or Chinese morning glory. Strongyloides larvae were most frequently detected in celery but in lettuce. Eggs of Trichuris trichiura were frequently detected in culantro but were not found in peppermint, lettuce, coriander, leek, gotu kola, or celery. Eggs of Ascaris lumbricoides were frequently detected in lettuce, coriander, and celery.

Table 2 shows the prevalence of parasitic contamination in different vegetable samples among the three markets. The parasites were detected in 51.5\%, 30.6\%, and $17.9 \%$ of samples obtained from Mueang, Thasala, and Sichon districts, respectively. The highest rate of parasitic contamination in vegetables was found in

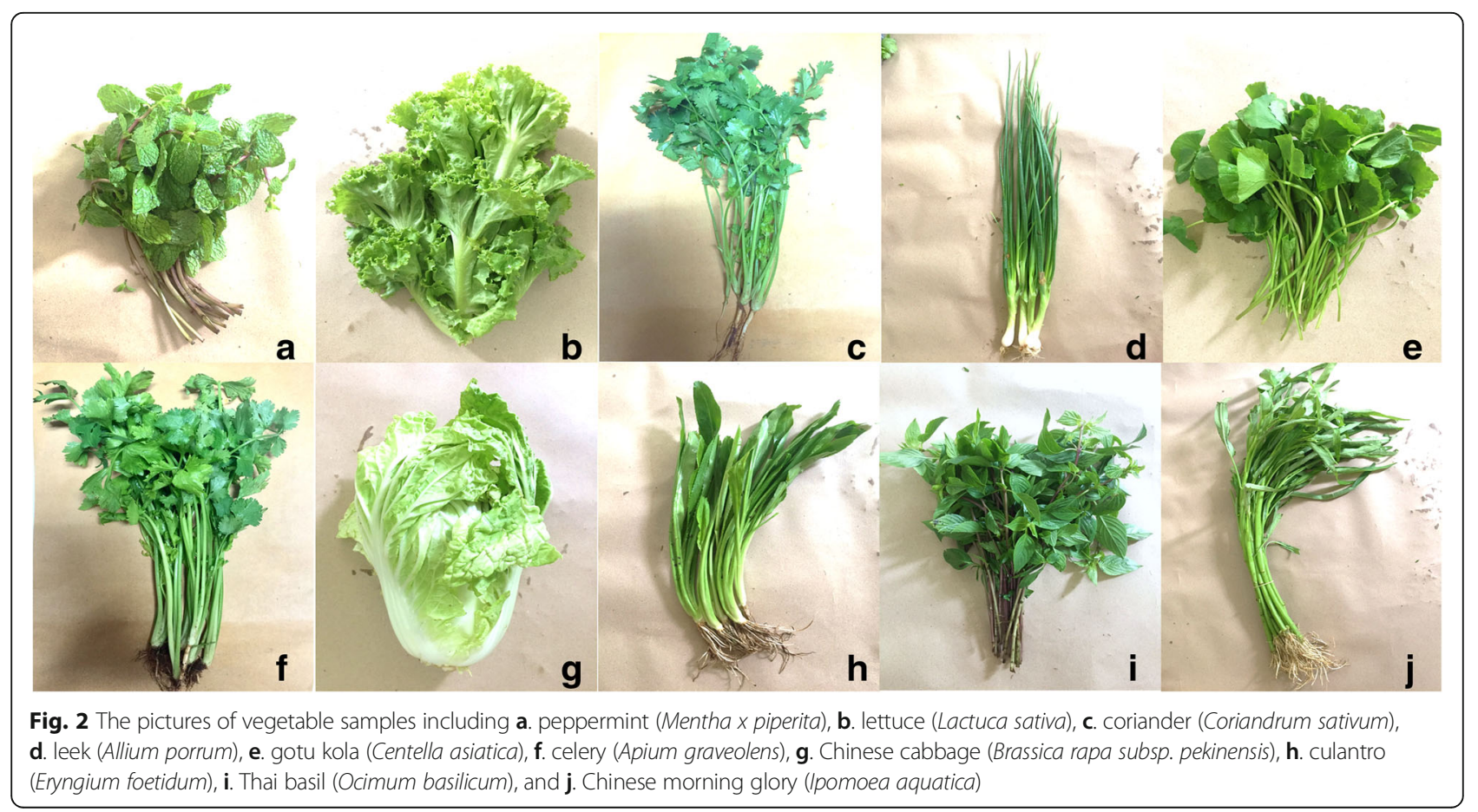


Table 1 Distribution of intestinal parasites in fresh vegetable samples collected from three markets in Nakhon Si Thammarat province, Thailand

\begin{tabular}{|c|c|c|c|c|c|c|c|}
\hline Vegetables & $\begin{array}{l}\text { Number of } \\
\text { sample }\end{array}$ & $\begin{array}{l}\text { Hookworm } \\
\text { Eggs (\%) }\end{array}$ & $\begin{array}{l}\text { Strongyloides } \\
\text { stercoralis larvae }\end{array}$ & $\begin{array}{l}\text { Trichuris trichiura } \\
\text { eggs }\end{array}$ & $\begin{array}{l}\text { Ascaris lumbricoides } \\
\text { eggs }\end{array}$ & $\begin{array}{l}\text { Toxocara spp. } \\
\text { eggs }\end{array}$ & $\begin{array}{l}\text { Number } \\
\text { positive (\%) }\end{array}$ \\
\hline Peppermint & 15 & $6(40.0)$ & $2(13.3)$ & 0 & 0 & $1(6.7)$ & $9(60.0)$ \\
\hline Lettuce & 20 & $1(5.0)$ & 0 & 0 & $3(15)$ & 0 & $4(20.0)$ \\
\hline Coriander & 29 & $8(27.6)$ & $2(6.9)$ & 0 & $3(10.3)$ & 0 & $13(44.8)$ \\
\hline Leek & 30 & $7(23.3)$ & $6(20.0)$ & 0 & 0 & 0 & $13(43.3)$ \\
\hline Gotu kola & 21 & $7(33.3)$ & $4(19.0)$ & 0 & 0 & $1(4.8)$ & $12(57.1)$ \\
\hline Celery & 30 & $9(30.0)$ & $9(30.0)$ & 0 & $1(3.3)$ & 0 & $19(63.3)$ \\
\hline Chinese cabbage & 30 & $2(6.7)$ & $1(3.3)$ & $2(6.7)$ & 0 & $2(6.7)$ & $7(23.3)$ \\
\hline Culantro & 30 & $4(13.3)$ & $2(6.7)$ & $3(10.0)$ & 0 & $2(6.7)$ & $11(36.7)$ \\
\hline Thai Basil & 30 & 0 & $1(3.3)$ & $1(3.3)$ & 0 & $1(3.3)$ & $3(10.0)$ \\
\hline Chinese morning glory & 30 & 0 & $1(3.3)$ & $1(3.3)$ & 0 & 0 & $2(6.7)$ \\
\hline Total & 265 & 44 (16.6) & 28 (10.6) & $7(2.6)$ & $7(2.6)$ & $7(2.6)$ & $93(35.1)$ \\
\hline
\end{tabular}

${ }^{a}$ Number of positive parasitic contamination events are significantly different among types of vegetables $(P<0.001)$

Mueang district, whereas the lowest rate was observed in Thasala district. Statistical analysis revealed that the rate of contamination in vegetables obtained from Mueang district was significantly higher than those obtained from Sichon and Thasala district $(P<0.001)$.

\section{Discussion}

The consumption of raw vegetables plays an important role in the transmission of parasites to humans. The recovery of parasites from vegetables helped us better understand the potential source of pathogenic parasite acquisition in this study area. This study demonstrated that the prevalence of parasitic contamination in vegetable samples from Nakhon $\mathrm{Si}$ Thammarat province was $35.1 \%$, which was comparable to the prevalence of $32.6 \%$ and $34.7 \%$ from previous reports in Shahrekord, Iran [16] and Poland [17], respectively. However, higher contamination rates, ranging from $45 \%$ to $58 \%$, were detected in Libya, Iran, Egypt, Brazil, and the Philippines [8, 13, 18-22]. In contrast,
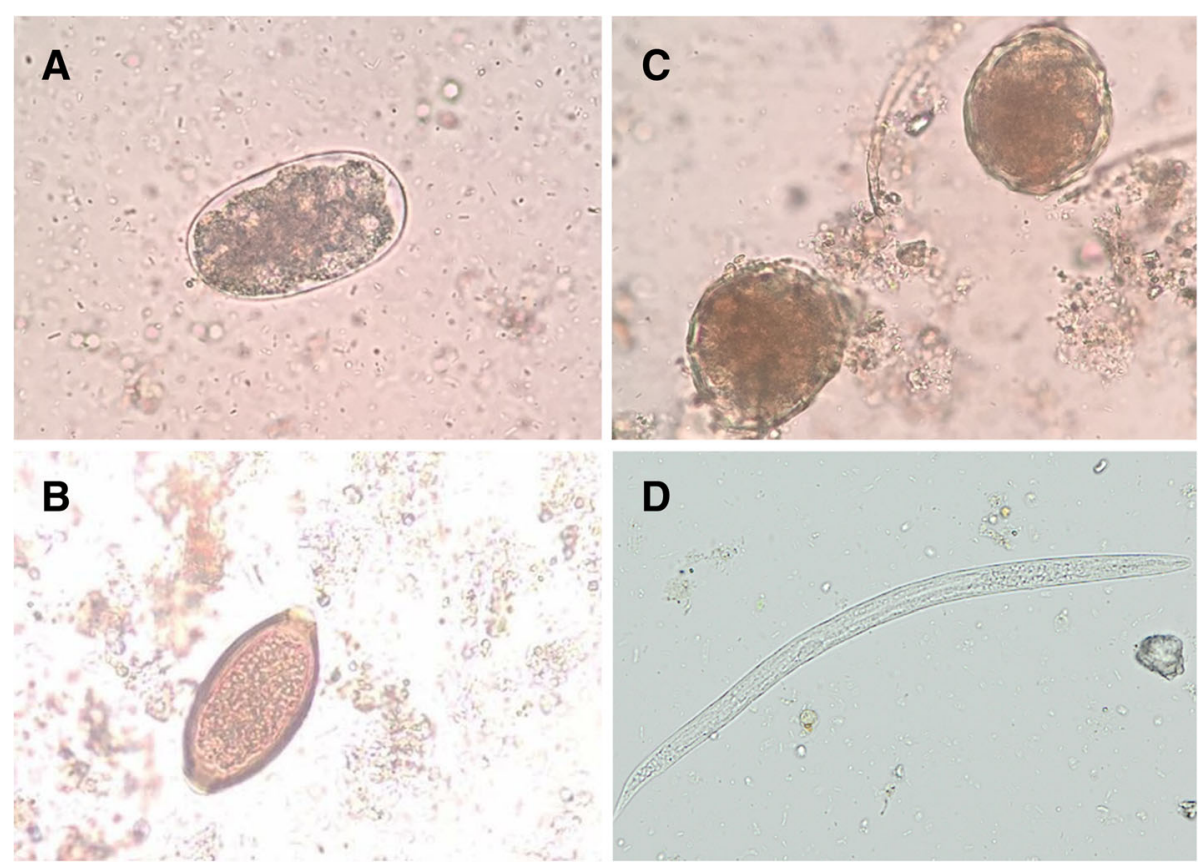

Fig. 3 Representative images of parasites found in this survey. Hookworm egg (a), Trichuris trichiura egg (b), Ascaris lumbricoides eggs (c) and Strongyloides stercoralis larvae (d). Original magnification: $40 \mathrm{X}$ 
Table 2 Distribution of intestinal parasite contamination in different fresh vegetables among the three markets in Nakhon Si Thammarat province, Thailand

\begin{tabular}{|c|c|c|c|c|c|c|c|c|}
\hline \multirow[t]{2}{*}{ Vegetable type } & \multicolumn{2}{|c|}{$\begin{array}{l}\text { No. of examined } \\
\text { samples }\end{array}$} & \multicolumn{2}{|c|}{ Mueang district } & \multicolumn{2}{|c|}{ Thasala district } & \multicolumn{2}{|c|}{ Sichon district } \\
\hline & Examined & Positive (\%) & $\begin{array}{l}\text { No. of } \\
\text { examined }\end{array}$ & $\begin{array}{l}\text { No. of positive } \\
\text { (\%) }\end{array}$ & $\begin{array}{l}\text { No. of } \\
\text { examined }\end{array}$ & $\begin{array}{l}\text { No. of positive } \\
(\%)\end{array}$ & $\begin{array}{l}\text { No. of } \\
\text { examined }\end{array}$ & $\begin{array}{l}\text { No. of positive } \\
(\%)\end{array}$ \\
\hline Peppermint & 15 & $9(60.0)$ & 11 & $7(63.6)$ & 0 & $0(0.0)$ & 4 & $4(40.0)$ \\
\hline Lettuce & 20 & $4(20.0)$ & 10 & $4(40.0)$ & 6 & $0(0.0)$ & 4 & $0(0.0)$ \\
\hline Coriander & 29 & $13(44.8)$ & 10 & $8(80.0)$ & 9 & $1(11.1)$ & 10 & $4(40.0)$ \\
\hline Leek & 30 & $13(43.3)$ & 10 & $6(60.0)$ & 10 & $4(40.0)$ & 10 & $3(30.0)$ \\
\hline Gotu kola & 21 & $12(57.1)$ & 10 & $7(70.0)$ & 3 & $2(66.7)$ & 8 & $3(37.5)$ \\
\hline Celery & 30 & $19(63.3)$ & 10 & $9(80.0)$ & 10 & $4(40.0)$ & 10 & $6(60.0)$ \\
\hline Chinese cabbage & 30 & $7(23.3)$ & 10 & $3(30.0)$ & 10 & $1(10.0)$ & 10 & $3(30.0)$ \\
\hline Culantro & 30 & $11(36.7)$ & 10 & $5(50.0)$ & 10 & $1(10.0)$ & 10 & $5(50.0)$ \\
\hline Thai Basil & 30 & $3(10.0)$ & 10 & $2(20.0)$ & 10 & $0(0.0)$ & 10 & $2(20.0)$ \\
\hline Chinese morning glory & 30 & $2(6.7)$ & 10 & $1(10.0)$ & 10 & $1(10.0)$ & 10 & $0(0.0)$ \\
\hline Total & 265 & $93(35.1)$ & 101 & $52(51.5)^{\mathrm{a}}$ & 78 & $14(17.9)^{a}$ & 85 & $26(30.6)^{a}$ \\
\hline
\end{tabular}

${ }^{a}$ Number of positive parasitic contamination events are significantly different among three markets $(P<0.001)$

the rate of contamination was lower in some studies, such as $5.9 \%$ in Ankara, Turkey [23], $14.89 \%$ in Mazandaran province, northern Iran [11], 19.4\% in Alexandria, Egypt [24], and 26\% in Hanoi, Vietnam [25]. According to the influence of season on the prevalence of parasites, previous studies reported that the rate of STH contamination was higher in warm seasons versus cold seasons [11, 19, 26]. This finding suggested that the transmission and prevalence rate of parasites were associated with climate and temperature. Differences between this study and others might be attributed to variations in climatic conditions, types of soil, types of water used for agriculture, and poor hygienic practices during the transportation and marketing of vegetables.

Celery was found to be the most frequently contaminated sample $(63.3 \%)$ followed by peppermint $(60.0 \%)$, gotu kola (57.1\%), coriander (44.8\%), leek (43.3\%), culantro (36.7\%), Chinese cabbage (23.3\%), lettuce (20\%), and Thai basil (20\%), whereas Chinese morning glory (6.7\%) was the least contaminated. These results were different from previous studies, which reported that lettuce possessed the highest parasitic contamination $[9,10,21]$. In Thailand, celery is commonly used for seasoning and garnishing in many Thai dishes. The highest contamination in celery might be because celery consists of a number of stalks that are connected at the base with its leaves near the top of stalks. The structure of its stalk is roughly U-shaped in a slit pattern, which allows the parasites to attach more easily to the surface of these vegetables and makes them more difficult to remove. Normally, celery samples obtained from the three markets were frequently sold with roots and stalks, which might increase the chance of soil contamination from roots to stalks. In contrast, the lowest parasitic contamination was observed in Chinese morning glory, which could be because the smooth surface of its stalks that may reduce the probability of parasitic attachment.

In this present study, hookworm was detected in $16.60 \%(44 / 265)$ of vegetables examined and was the most predominant pathogenic parasite. This finding is in agreement with other studies conducted in Ghana (13\%) [4], Sudan (5.7\%) [9], and northern Iran (4.40\%) [11]. In contrast, no ova of hookworm species were recovered in some previous studies $[8,10,16,18-20,22-25,27]$. Our previous report in 2017 demonstrated that hookworm infection was the most prevalent parasitic infection in Nopphitam district, Nakhon Si Thammarat province, southern Thailand [2]. The high prevalence of hookworm egg contamination of vegetables in this study could be attributed to poor sanitation and the use of human waste-contaminated water for irrigation in the region. Lack of proper footwear and exposure of skin to contaminated soil might be responsible for hookworm infection in the study area. In addition, the high prevalence of hookworm might be due to differences in geographical location, climate conditions, and the types of soil $[28,29]$. The second most prevalent contamination found in this study was the larvae of Strongyloides stercoralis. Our finding was consistent with previous studies in Accra, Ghana and in Jimma Town, Ethiopia, which reported a $43 \%$ and $21.9 \%$ prevalence of Strongyloides stercoralis contamination, respectively [4, 22]. A high rate of Strongyloides contamination might be because Strongyloides spp. has a complex life cycle with a free-living stage in the environment that does not require a host for its proliferation [30]. 
Aside from the contamination of hookworm eggs, $T$. trichiura and Ascaris lumbricoides eggs were also detected in the vegetable samples collected from this area. Trichuriasis occurs by ingestion of contaminated food and water with embryonated eggs of T. trichiura [31]. In the present study, eggs of $T$. trichiura were detected in $2.64 \%(7 / 265)$ of vegetable samples. This finding was consistent with previous reports from Khartoum state, Sudan [9], Mazandaran province, northern Iran [11], Accra, Ghana [4] and in villages of Qazvin province, Iran [27], where the contamination rates were 2.9, 2.2, 2 and $0.9 \%$, respectively. In addition, eggs of Ascaris lumbricoides were detected in $2.64 \%(7 / 265)$ of vegetable samples. The rate of contamination with $A$. lumbricoides eggs was $68 \%$ in Tripoli, Libya [18], 20.83\% in Arba Minch town, southern Ethiopia [8] and 8.17\% in Shahrekord, Iran [26]. Contamination by these STHs in vegetable samples might occur at any point along the chain; during planting, harvesting, transportation, or the marketing of vegetables. The differences in the degree of contamination might be attributed to the types of soil, the quality of water used for planting and irrigation, and hygienic practices during the process of marketing.

Beside STH contamination, this study also detected Toxocara spp. eggs in $2.64 \%(7 / 265)$ of fresh vegetable samples. In other locales, the rate of contamination with Toxocara spp. eggs in vegetables was $37 \%$ in Libya [18], 15.83\% in Arba Minch town, southern Ethiopia [8], 3.3\% in Shahrekord, Iran [16], 3\% in Hanoi, Vietnam [25], and 1.5\% in Ankara, Turkey [23]. In contrast, no ova of Toxocara spp. in vegetables were reported in Ardabil, Khorramabad, and Qasvin, Iran, Accra, Ghana, Benha and Alexandria, Egypt, Minas Gerais, Brazil, or Khartoum state, Sudan $[4,9,10,19-21,24,27]$. Human toxocariasis is a helminthic zoonosis caused by larval stages of Toxocara canis and less frequently by Toxocara cati [32]. The long term survival of Toxocara spp. outside their hosts coupled with their high fecundity is responsible for significant contamination of soil with infective eggs [32]. This study indicates that domestic animals (dogs and cats), which are the source of Toxocara eggs, may at some point shed contaminated feces onto cultivation areas.

The parasitic contamination rates were significantly different for samples collected from different markets; samples collected from Muang district showed the highest rate of contamination. The differences between the three markets might be due to the different sources of vegetables as well as the hygienic practices in handling and washing by different sellers.

The results of this study emphasized that raw vegetables from the markets in the study area could be possible vehicles of parasitic transmission to humans. The previous studies revealed that the standard washing procedure was an effective method to prevent the contaminations of helminths in raw vegetables [16, 23, 33]. Furthermore, to emphasize on the proper washing procedure, the previous study in Iran demonstrated that the pre-washing procedure using tap water or underground water could not completely get rid of parasites from vegetables [26]. Hence, the health authorities should provide the knowledge of proper washing method for local people in order to prevent parasitic transmission.

However, it is important to note that our study has several limitations. This study did not demonstrate the effect of seasonal variation on parasitic contamination. We did not address the intensity of vegetable washing before display for sale or the source of water used by each seller. These factors might affect the rate of vegetable contamination in our study.

\section{Conclusion}

The results of the present study indicate that the contamination of raw vegetables with pathogenic parasites in Nakhon Si Thammarat province, southern Thailand might represent a transmission vector for intestinal parasites to consumers. Prevention methods such as proper washing or cooking of vegetables before consumption should be conveyed to consumers. In addition, comprehensive health education and hygienic practices, including wearing gloves and washing hands after handling vegetables, should be provided to sellers and farmers.

\section{Abbreviations}

STH: Soil-transmitted helminth; WHO: World Health Organization

\section{Acknowledgements}

The authors wish to thank the vegetable sellers who participated in the study. The authors would like to acknowledge Dr. Prachyapan Petchuay, MD, PhD, Dean School of Medicine, Walailak University for their support throughout the course of this study. We also thank Miss Potiga Chotipong for preparing reagents and laboratory instruments.

\section{Funding}

This study was partially financially supported by the Tropical Diseases and Parasitic Infectious Diseases Research Group (WU60512), granted by the Institute of Research and Development, Walailak University. The funder played no role in the study design, data collection, and data analysis and interpretation.

\section{Availability of data and materials}

All data generated or analyzed during this study are available from the corresponding author on reasonable request.

\section{Authors' contributions}

$K T$, SN, NP, PV, and CP conceived and designed the study. KT, SN, NP, and CP performed data collection. KT, SN, NP, PV, and CP performed the experiments. $K T$, NP, PV, and CP analyzed the data. NP, PV, and CP wrote the manuscript. All authors read and approved the final manuscript.

\section{Ethics approval and consent to participate}

This study protocol was reviewed and approved by the Ethics Committee on Human Rights Related to Research Involving Human Subjects, Walailak University prior to the collection of samples (Protocol No. WU-EC-MD-4-118-59). 


\section{Competing interests}

The authors declare that they have no competing interests.

\section{Publisher's Note}

Springer Nature remains neutral with regard to jurisdictional claims in published maps and institutional affiliations.

\section{Author details}

'School of Medicine, Walailak University, 222 Thasala district, Nakhon Si Thammarat 80161, Thailand. 'Department of Tropical Pathology, Faculty of Tropical Medicine, Mahidol University, Bangkok 10400, Thailand. ${ }^{3}$ Tropical Medicine Research Unit, Research Institute for Health Sciences, Walailak University, 222 Thasala district, Nakhon Si Thammarat 80161, Thailand.

Received: 26 June 2018 Accepted: 21 December 2018

Published online: 08 January 2019

\section{References}

1. Jongsuksuntigul $P$, Manatrakul D, Wongsaroj T, Krisanamara K, Sawatdimongkol S, Wongsaroj S. Evaluation of helminthiasis control program in Thailand at the end of the 8th health development plan, 2001. J Trop Med Parasitol. 2003:26:38-46.

2. Punsawad C, Phasuk N, Bunratsami S, Thongtup K, Siripakonuaong N, Nongnaul S. Prevalence of intestinal parasitic infection and associated risk factors among village health volunteers in rural communities of southern Thailand. BMC Public Health. 2017;17(1):564.

3. Wongsaroj T, Nithikathkul C, Rojkitikul W, Nakaia W, Royal L, Rammasut P. National survey of helminthiasis in Thailand. Asian Biomed. 2014;8:779-83.

4. Duedu KO, Yarnie EA, Tetteh-Quarcoo PB, Attah SK, Donkor ES, Ayeh-Kumi PF. A comparative survey of the prevalence of human parasites found in fresh vegetables sold in supermarkets and open-aired markets in Accra, Ghana. BMC Res Notes. 2014;7:836.

5. Hookworm FAQs [https://www.cdc.gov/parasites/hookworm/gen_info/fags.html].

6. Fruit and Vegetables for Health. Report of a Joint FAO/WHO Workshop, 1-3 September 2004, Kobe, Japan [http://apps.who.int/iris/bitstream/10665/ 43143/1/9241592818_eng.pdf?ua=1\&ua=1].

7. Berger CN, Sodha SV, Shaw RK, Griffin PM, Pink D, Hand P, Frankel G. Fresh fruit and vegetables as vehicles for the transmission of human pathogens. Environ Microbiol. 2010;12(9):2385-97.

8. Bekele F, Tefera T, Biresaw G, Yohannes T. Parasitic contamination of raw vegetables and fruits collected from selected local markets in Arba Minch town, Southern Ethiopia. Infect Dis Poverty. 2017;6(1):19.

9. Mohamed MA, Siddig EE, Elaagip AH, Edris AM, Nasr AA. Parasitic contamination of fresh vegetables sold at central markets in Khartoum state, Sudan. Ann Clin Microbiol Antimicrob. 2016;15:17.

10. Eraky MA, Rashed SM, Nasr Mel S, El-Hamshary AM, Salah El-Ghannam A Parasitic contamination of commonly consumed fresh leafy vegetables in benha, Egypt. J Parasitol Res. 2014;2014:613960.

11. Rostami A, Ebrahimi M, Mehravar S, Fallah Omrani V, Fallahi S, Behniafar H. Contamination of commonly consumed raw vegetables with soil transmitted helminth eggs in Mazandaran province, northern Iran. Int J Food Microbiol. 2016;225:54-8.

12. Robertson $\sqcup$, Troell K, Woolsey ID, Kapel CM. Fresh fruit, vegetables, and mushrooms as transmission vehicles for Echinococcus multilocularis in Europe: inferences and concerns from sample analysis data from Poland. Parasitol Res. 2016;115(6):2485-8.

13. Sia Su G, Mariano C, Matti N, Ramos G. Assessing parasitic infestation of vegetables in selected markets in Metro Manila, Philippines. Asian Pac J Trop Dis. 2012;2:51-4.

14. Hong S, Kim K, Yoon S, Park WY, Sim S, Yu JR. Detection of Cryptosporidium parvum in environmental soil and vegetables. J Korean Med Sci. 2014;29(10): 1367-71.

15. Tram NT, Dalsgaard A. Water used to moisten vegetables is a source of Escherichia coli and protozoan parasite contamination at markets in Hanoi, Vietnam. J Water Health. 2014;12(4):896-900

16. Fallah AA, Pirali-Kheirabadi K, Shirvani F, Saei-Dehkordi SS. Prevalence of parasitic contamination in vegetables used for raw consumption in Shahrekord, Iran: influence of season and washing procedure. Food Control. 2012;25(2):617-20
17. Klapec T, Borecka A. Contamination of vegetables, fruits and soil with geohelmints eggs on organic farms in Poland. Ann Agric Environ Med. 2012;19(3):421-5.

18. Abougrain AK, Nahaisi MH, Madi NS, Saied MM, Ghenghesh KS. Parasitological contamination in salad vegetables in Tripoli-Libya. Food Control. 2010;21(5):760-2.

19. Daryani A, Ettehad GH, Sharif M, Ghorbani L, Ziaei H. Prevalence of intestinal parasites in vegetables consumed in Ardabil, Iran. Food Control. 2008;19(8): $790-4$.

20. Ezatpour B, Chegeni AS, Abdollahpour F, Aazami M, Alirezaei M. Prevalence of parasitic contamination of raw vegetables in Khorramabad, Iran. Food Control. 2013;34(1):92-5

21. Luz JGG, Barbosa MV, de Carvalho AG, Resende SD, Dias JVL, Martins HR. Contamination by intestinal parasites in vegetables marketed in an area of Jequitinhonha Valley, Minas Gerais, Brazil. Revista De Nutricao-Brazilian Journal of Nutrition. 2017;30(1):127-36.

22. Tefera T, Biruksew A, Mekonnen Z, Eshetu T. Parasitic contamination of fruits and vegetables collected from selected local Markets of Jimma Town, Southwest Ethiopia. Int Sch Res Notices. 2014;2014:382715.

23. Kozan E, Gonenc B, Sarimehmetoglu O, Aycicek H. Prevalence of helminth eggs on raw vegetables used for salads. Food Control. 2005;16(3):239-42.

24. Hassan A, Farouk H, Abdul-Ghani R. Parasitological contamination of freshly eaten vegetables collected from local markets in Alexandria, Egypt: a preliminary study. Food Control. 2012;26(2):500-3.

25. Uga S, Hoa NT, Noda S, Moji K, Cong L, Aoki Y, Rai SK, Fujimaki Y. Parasite egg contamination of vegetables from a suburban market in Hanoi, Vietnam. Nepal Med Coll J. 2009;11(2):75-8.

26. Fallah AA, Makhtumi Y, Pirali-Kheirabadi K. Seasonal study of parasitic contamination in fresh salad vegetables marketed in Shahrekord, Iran. Food Control. 2016;60:538-42.

27. Shahnazi M, Jafari-Sabet M. Prevalence of parasitic contamination of raw vegetables in villages of Qazvin Province, Iran. Foodborne Pathog Dis. 2010; 7(9):1025-30.

28. Brooker S, Bethony J, Hotez PJ. Human hookworm infection in the 21st century. Adv Parasitol. 2004:58:197-288.

29. Silver ZA, Kaliappan SP, Samuel P, Venugopal S, Kang G, Sarkar R, Ajjampur SSR. Geographical distribution of soil transmitted helminths and the effects of community type in South Asia and South East Asia - a systematic review. PLoS Negl Trop Dis. 2018:12(1).

30. Schar F, Trostdorf U, Giardina F, Khieu V, Muth S, Marti H, Vounatsou P, Odermatt P. Strongyloides stercoralis: global distribution and risk factors. PLoS Negl Trop Dis. 2013;7(7).

31. Parija SC, Chidambaram M, Mandal J. Epidemiology and clinical features of soil-transmitted helminths. Trop Parasitol. 2017:7(2):81-5.

32. Thomas $D$, Jeyathilakan N. Detection of Toxocara eggs in contaminated soil from various public places of Chennai city and detailed correlation with literature. J Parasit Dis. 2014;38(2):174-80.

33. Avcioglu $H_{\text {, Soykan }}$, Tarakci U. Control of helminth contamination of raw vegetables by washing. Vector Borne Zoonotic Dis. 2011;11(2):189-91.

\section{Ready to submit your research? Choose BMC and benefit from:}

- fast, convenient online submission

- thorough peer review by experienced researchers in your field

- rapid publication on acceptance

- support for research data, including large and complex data types

- gold Open Access which fosters wider collaboration and increased citations

- maximum visibility for your research: over $100 \mathrm{M}$ website views per year

At $\mathrm{BMC}$, research is always in progress.

Learn more biomedcentral.com/submissions 